\title{
Properties of a Mutant of Escherichia coli with a Temperature-sensitive Fructose-1,6-Diphosphate Aldolase
}

\author{
AUGUST BÖCK ${ }^{1}$ AND FREDERICK C. NEIDHARDT \\ Department of Biological Sciences, Purdue University, Lafayette, Indiana
}

Received for publication 31 March 1966

\begin{abstract}
Böck, August (Purdue University, Lafayette, Ind.), AND Frederick C. NeidHARDT. Properties of a mutant of Escherichia coli with a temperature-sensitive fructose-1 ,6-diphosphate aldolase. J. Bacteriol. 92:470-476. 1966.-A mutant of Escherichia coli in which fructose-1,6-diphosphate aldolase functions at $30 \mathrm{C}$ but not at $40 \mathrm{C}$ was used to study the physiological effect of a specific block in the Embden-Meyerhof glycolytic pathway. Growth of the mutant at $40 \mathrm{C}$ was found to be inhibited by the presence of glucose or certain related compounds in the medium. At $40 \mathrm{C}$, glucose was metabolized at 30 to $40 \%$ of the control rate and was abnormal in that glucose was converted into other six-carbon substances (probably gluconate, in large part) that were released into the culture medium. The inhibition was complete, but transient; its duration depended upon the initial amount of inhibitor added. The resumption of growth at $40 \mathrm{C}$ was correlated with the further catabolism of the excreted compounds. When glycerol was used to grow the mutant at $40 \mathrm{C}$, the growth inhibition by glucose was accompanied by cessation of glycerol metabolism. Growth on $\alpha$-glycerol phosphate was not inhibited under these conditions, implicating glycerol kinase as a possible site of inhibition; no inhibition of glycerol kinase by sugar phosphates, however, could be detected in vitro. The inhibitory effect of glucose on growth at $40 \mathrm{C}$ is not caused by a deficit of intracellular adenosine triphosphate, but may be the result of a generalized poisoning of many cell processes by a greatly increased intracellular concentration of fructose-1,6-diphosphate, the substrate of the damaged enzyme.
\end{abstract}

In the preceding paper (2) we reported the isolation of a mutant of Escherichia coli possessing a temperature-sensitive fructose-1,6-diphosphate aldolase. The mutant enzyme appears to function in vivo at $30 \mathrm{C}$ but not at $40 \mathrm{C}$, and no activity can be detected in vitro at either temperature.

Initial experiments on the physiological consequences of damaged aldolase activity quickly revealed two unexpected properties of the mutant: (i) it can grow normally at $40 \mathrm{C}$ in minimal media with glycerol or succinate as sole carbon and energy sources, whereas aldolase activity should be necessary for pentose synthesis from these substrates; and (ii) it fails to grow at $40 \mathrm{C}$ in any medium containing even trace amounts of glucose or certain related compounds.

This paper reports an analysis of these consequences of a metabolic block in the EmbdenMeyerhof pathway.

${ }^{1}$ On leave from the Department of Botany, University of Munich, Germany.

\section{Materials AND MethodS}

Organisms. Two strains of $E$. coli were used in this study: K-10, a thiamine-requiring wild strain, and its derivative, h8, a mutant with a temperature-sensitive aldolase (2). The media used have been described recently (7). Growth was measured by optical density (OD) in a spectrophotometer (model PMQ II; Carl Zeiss, Inc., New York, N. Y.) at $420 \mathrm{~m} \mu$.

Preparation of acid-soluble cell fraction. The cells from $200 \mathrm{ml}$ of rapidly chilled culture (OD, 1.0) were collected by centrifugation and then suspended in $1 \mathrm{ml}$ of $10 \% \mathrm{HClO}$ at $0 \mathrm{C}$. The mixture was carefully neutralized with approximately $0.85 \mathrm{ml}$ of $2 \mathrm{~N} \mathrm{KOH}$. Immediately, $2 \mathrm{ml}$ of $0.05 \mathrm{M}$ glycine buffer $(p \mathrm{H} \mathrm{7.4)}$ was added [as suggested by Imsande and Prestidge (16)], and the extract was clarified by centrifugation. Portions of the supernatant fluid were analyzed at once for adenosine triphosphate (ATP) and sugar phosphates..

Chemical and enzymatic determinations. Glucose was measured with the commercial preparation, Glucostat (Worthington Biochemical Corp., Freehold, N. J.), which contains glucose oxidase, peroxi- 
dase, and a chromogen. Glycerol was measured by colorimetric assay of the formaldehyde produced by periodate oxidation (20). Reducing compounds were estimated by the phenol-sulfuric acid method (6). The oxidation of $\mathrm{C}^{14}$-labeled glucose was followed by methods described in the companion paper (2).

Glucose-6-phosphate and fructose-1,6-diphosphate were measured by conventional enzymatic methods employing spectrophotometry: glucose-6-phosphate by glucose-6-phosphate dehydrogenase-mediated reduction of nicotinamide adenine dinucleotide phosphate (15); and fructose-1,6-diphosphate by an aldolase and glyceraldehyde-3-phosphate dehydrogenase-coupled reduction of nicotinamide adenine dinucleotide (19), correcting for the presence of triose phosphate by the value obtained in the absence of aldolase. Enzymes used in these assays were obtained from the Sigma Chemical Co., St. Louis, Mo., as crystalline $\left(\mathrm{NH}_{4}\right)_{2} \mathrm{SO}_{4}$ suspensions.

The ATP content of cells was determined by measuring the light-producing capacity of portions of the $\mathrm{HClO}_{4}$ extracts with a crude firefly preparation (4). The reaction mixture contained, in a final volume of $3.0 \mathrm{ml}: 0.1 \mathrm{ml}$ of $0.1 \mathrm{M} \mathrm{MgSO}{ }_{4}, 0.3 \mathrm{ml}$ of crude firefly extract, and $2.3 \mathrm{ml}$ of $0.025 \mathrm{M}$ tris(hydroxymethyl)aminomethane- $\mathrm{H}_{2} \mathrm{SO}_{4}(p \mathrm{H}$ 7.5). The reaction was started by injecting $0.3 \mathrm{ml}$ of the sample with a syringe. Light production was measured in a spectrophotometer (model DU; Beckman Instruments, Inc., Fullerton, Calif.). Total light-producing capacity was used to determine "apparent ATP"; the fraction sensitive to incubation with hexokinase, glucose, and $\mathrm{MgCl}_{2}$ was assumed to be "true ATP."

Glycerol kinase was measured by the method of Bublitz and Kennedy (3). $\beta$-Galactosidase was measured by the method of Herzenberg (14).

\section{RESULTS}

Inhibition of growth at $40 \mathrm{C}$ by glucose. The mutant, h8, was originally isolated as a strain that could grow in a glucose-yeast extracttryptone medium at $30 \mathrm{C}$ but not at $40 \mathrm{C}$. The lowest growth curve in Fig. 1 illustrates the inhibition of a culture of h8 in this medium when the temperature was raised from 30 to $40 \mathrm{C}$. The same figure shows the growth of a similar culture lacking glucose; growth was slightly faster at $30 \mathrm{C}$ in the absence of glucose, and the growth accelerated at $40 \mathrm{C}$ after a short transition lag. Addition of glucose $(0.2 \%)$ to a third culture at the time of the temperature shift inhibited growth, but permitted an approximately $50 \%$ increase in OD.

The growth experiment reported in Fig. 2 demonstrated two characteristics of the growth inhibition caused by glucose at $40 \mathrm{C}$ : (i) as little as $1 \mu \mathrm{g} / \mathrm{ml}$ of glucose suffices to inhibit growth of h8 at $40 \mathrm{C}$ in a glycerol-containing minimal medium, and (ii) the duration of the inhibition is a function of the concentration of glucose added, $1 \mu \mathrm{g} / \mathrm{ml}$ being inhibitory for $20 \mathrm{~min}, 10 \mu \mathrm{g} / \mathrm{ml}$ for $2.5 \mathrm{hr}$, and $100 \mu \mathrm{g} / \mathrm{ml}$ for $7 \mathrm{hr}$. In other experi-

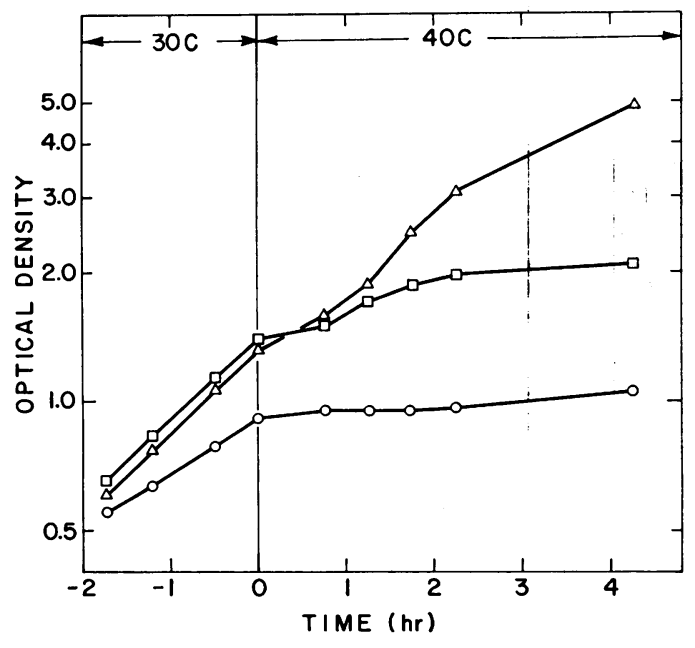

Fig. 1. Effect of temperature and glucose on the growth of mutant h8 in rich media. Growth (optical density at $420 \mathrm{m \mu}$ ) is plotted on a logarithmic scale as a function of time for three cultures shifted at zero-time from 30 to $40 \mathrm{C}$. All cultures were growing on tryptoneyeast extract, with no glucose present $(\triangle)$, with glucose $(0.2 \%)$ added at zero-time $(\square)$, or with glucose $(0.2 \%)$ present from the beginning of the experiment (O).

ments (not shown), the ability of $10 \mu \mathrm{g} / \mathrm{ml}$ of glucose to inhibit growth on glycerol quickly and totally for $2.5 \mathrm{hr}$ was found to be unaffected by varying the glycerol concentration from 0.1 to $4.0 \%$.

Inhibition of growth at $40 \mathrm{C}$ by other substances. The addition of fructose, galactose, gluconate, ribose, or lactose at a concentration of $0.2 \%$ to cultures of $\mathrm{h} 8$ growing on glycerol at $40 \mathrm{C}$ resulted in an inhibition similar to that caused by glucose. In the case of fructose, the effect was immediate; the other compounds inhibited only after a short lag. The effect of lactose addition is shown in Fig. 3. Samples of the culture were removed at intervals to be assayed for $\beta$-galactosidase activity. The results indicate that lactose became inhibitory to growth only after $\beta$-galactosidase had been formed.

Substrate metabolism during growth inhibition. To discover the cause of the growth inhibition, the disappearance of glycerol from the growth medium was measured in a culture of the mutant (growing on this substrate) shifted from 30 to $40 \mathrm{C}$; in a parallel culture, glucose $(0.2 \%)$ was added at the time of the temperature shift, and samples of the medium were taken at intervals to be assayed for both glucose and glycerol (Fig. 4). The control culture exhibited a normal rate of glycerol uptake at $40 \mathrm{C}$. In the experimental culture, glycerol uptake was totally abolished by the addition of glucose, and glucose was con- 


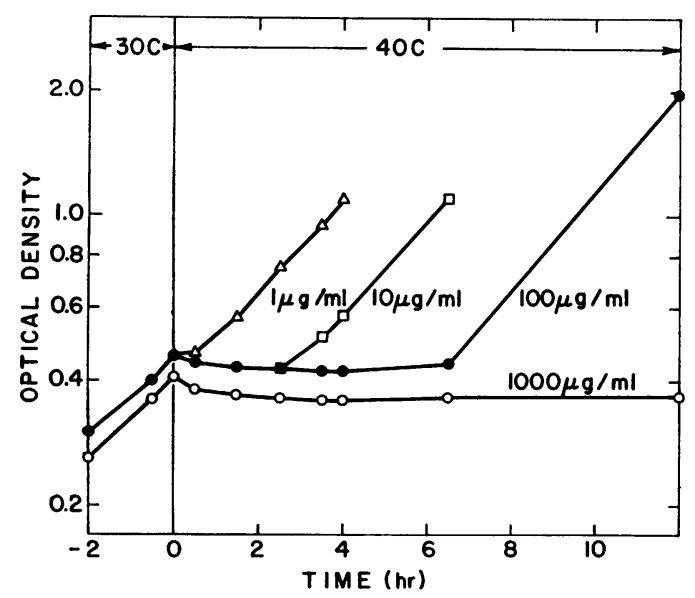

FiG. 2. Effect of different glucose concentrations on the growth of mutant h8 in glycerol minimal medium at 40 C. Growth (optical density at $420 \mathrm{m \mu}$ ) is plotted on a logarithmic scale as a function of time for four parallel cultures shifted from 30 to $40 \mathrm{C}$ at zero-time. Glucose was added at zero-time to each culture to give a concentration of $1 \mu \mathrm{g} / \mathrm{ml}(\triangle), 10 \mu \mathrm{g} / \mathrm{ml}(\square), 100 \mu \mathrm{g} / \mathrm{ml}(\mathrm{O})$, or $1,000 \mu \mathrm{g} / \mathrm{ml}(\mathrm{O})$.

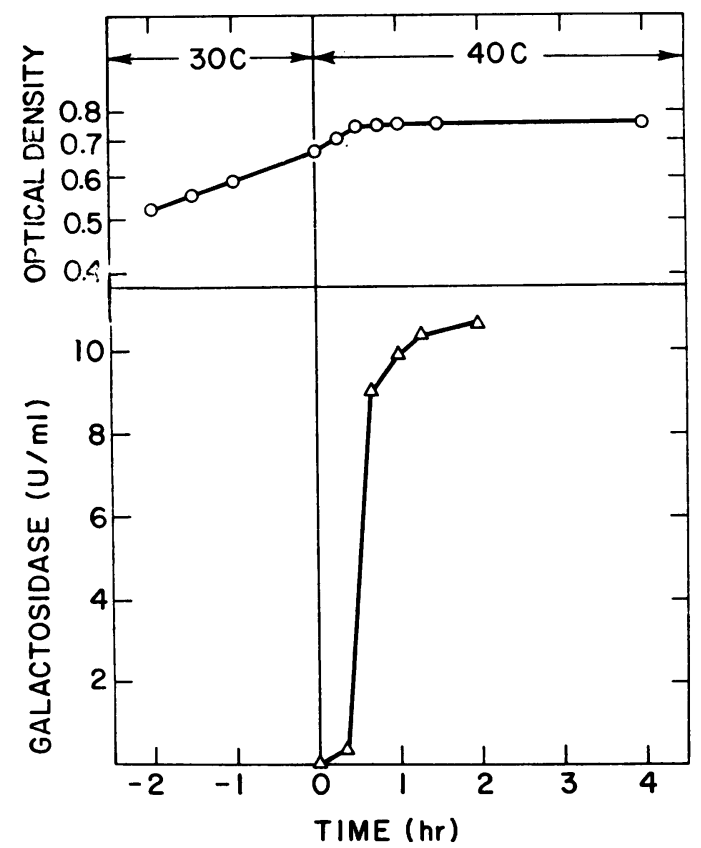

FIG. 3. Growth and $\beta$-galactosidase synthesis after the addition of lactose to a culture of h8 growing on glycerol minimal medium. Growth (optical density at $420 \mathrm{m \mu}$ ) is plotted on a logarithmic scale as a function of time (O), and $\beta$-galactosidase (units of enzyme per milliliter of culture) on a linear scale $(\triangle)$. At zero-time, the temperature was raised from 30 to $40 C$ and lactose $(0.2 \%)$ was added to the culture.

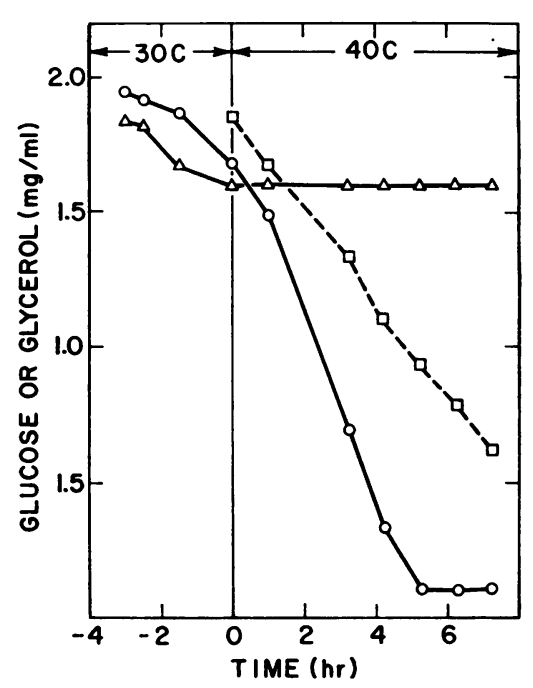

FIG. 4. Utilization of glycerol and glucose by cultures of h8 at $40 \mathrm{C}$. Two parallel cultures of h8 growing in glycerol minimal medium were shifted from 30 to $40 \mathrm{C}$ at zero-time (1.25 optical density units at zero-time). One culture received no addition, and the amount of glycerol present in the medium was measured and plotted as a function of time (O). The second culture received glucose $(0.2 \%)$ at zero-time. The amount of glycerol $(\triangle)$ and of glucose $(\square)$ present in the medium is plotted as a function of time.

sumed at a rate of 1.6 to $2.0 \mathrm{mg}$ per $\mathrm{mg}$ of protein per hr.

To study the fate of the glucose metabolized during the growth inhibition, the mutant was grown in glycerol minimal medium at $40 \mathrm{C}$, and $500 \mu \mathrm{g} / \mathrm{ml}$ of glucose- $1-C^{14}(0.07 \mu \mathrm{c} / \mathrm{ml})$ was added to the culture. Samples were removed at hourly intervals for the next $5 \mathrm{hr}$ and assayed for radioactivity and for glucose by the Glucostat method; in addition, respiratory $\mathrm{CO}_{2}$ was trapped in a $\mathrm{KOH}$-containing well, and its radioactivity was measured at hourly intervals (Fig. 5). Glucose, as measured by Glucostat, disappeared rapidly from the medium within $3 \mathrm{hr}$. Over the same interval, however, only $5 \%$ of the radioactive label appeared in the respiratory $\mathrm{CO}_{2}$; the remainder was recovered in the medium. When this experiment was repeated with uniformly $\mathrm{C}^{14}$-labeled glucose, approximately $10 \%$ of the label appeared as $\mathrm{CO}_{2}$ at the time of complete glucose disappearance.

These results make it clear that glucose is not degraded to the normal end products of aerobic metabolism, but is converted into some (one or more) metabolite which is released into the medium and which is responsible for the continued growth inhibition. 


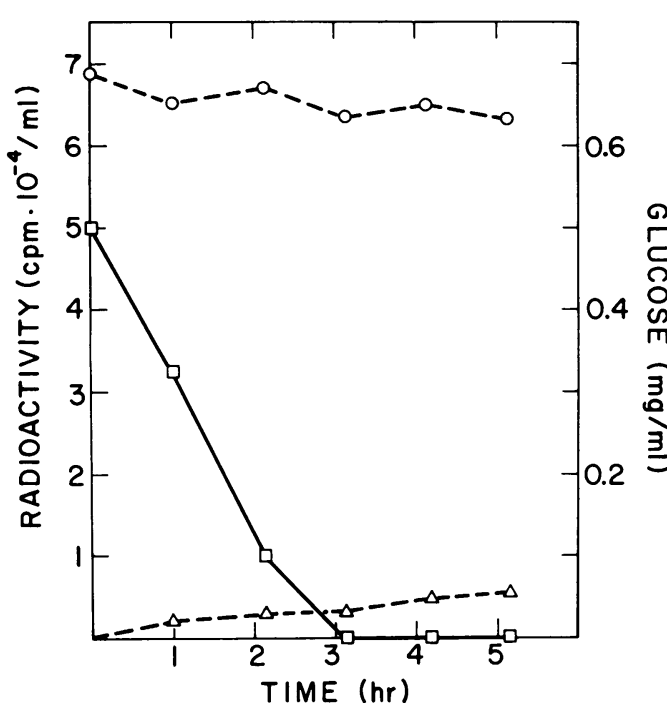

Fig. 5. Metabolism of glucose-1-C $C^{14}$ by a culture of h8 at $40 \mathrm{C}$. A culture growing in glycerol minimal medium (1.09 optical density units at zero-time) received $500 \mu \mathrm{g} / \mathrm{ml}$ of glucose- $1-\mathrm{C}^{14}(0.07 \mu \mathrm{c} / \mathrm{ml})$ at zerotime. Samples removed at hourly intervals were assayed for radioactivity remaining in the medium $(O)$, radioactivity in respiratory $\mathrm{CO}_{2}(\triangle)$, and glucose remaining in the medium as assayed by the Glucostat method ( $\square)$.

Properties of the excreted metabolite. To test the inhibitory capacity of the excreted metabolite(s), a portion of the medium from the culture described above (and shown in Fig. 5) was removed at a time when all of the radioactive glucose had been converted into the unknown compound(s). After removal of the cells by centrifugation, $0.5 \mathrm{ml}$ of the medium (which originally had contained $500 \mu \mathrm{g} / \mathrm{ml}$ of glucose) was added to $20 \mathrm{ml}$ of a culture of the mutant growing in glycerol minimal medium at $40 \mathrm{C}$. Samples of the culture were removed at hourly intervals to measure OD and the radioactivity of the medium (Fig. 6). Addition of the medium containing the excreted metabolite inhibited growth for approximately $3 \mathrm{hr}$, during which time $90 \%$ of the label originally in carbon 1 of glucose disappeared from the medium. (Less than $1 \%$ of this was incorporated into cell material.) Growth of the culture resumed at this time.

The inhibitory compound gave no color reaction with the phenol-sulfuric acid reagent of Dubois et al. (6) and therefore neither has reducing groups nor is hydrolyzed by this reagent to yield reducing substances. This result indicates that fructose-1,6-diphosphate is probably not a major component of the excreted substances, which would thus appear to be nonreducing

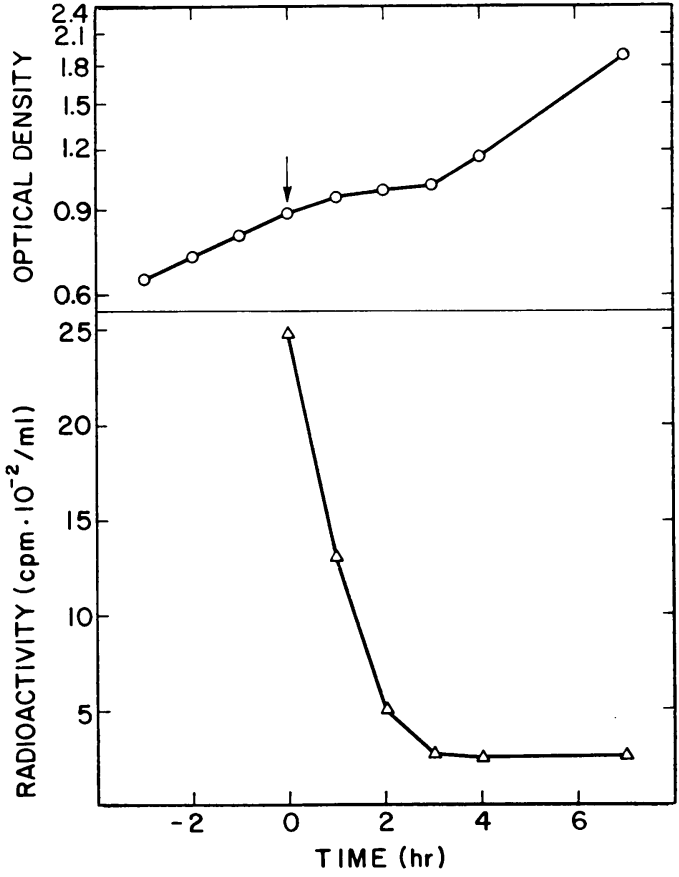

FIG. 6. Inhibitory effect of glucose metabolites on growth of h8 on glycerol minimal medium at $40 \mathrm{C}$. At zero-time, $0.5 \mathrm{ml}$ of medium containing metabolites previously excreted by $h 8$ cells during metabolism of glucose- $1-C^{14}$ at $40 \mathrm{C}$ was added to $20 \mathrm{ml}$ of a culture of h8 grown on glycerol at 40 C. Growth (optical density at $420 \mathrm{m \mu}$ ) is plotted as a logarithmic function of time $(O)$ and radioactivity remaining in the medium as a linear function $(\triangle)$.

compounds that can be almost completely decarboxylated in the $\mathrm{C} 1$ position by mutant $\mathrm{h} 8$. These properties would all be possessed by gluconate. In three different solvents, the metabolite(s) had the same $R_{F}$ on paper chromatograms as did gluconate, but a more thorough identification has not been made.

Mechanism of the inhibition. Growth on succinate at $40 \mathrm{C}$ was not halted as rapidly by glucose as was growth on glycerol. The results in Fig. 7 demonstrate the sluggish nature of the response of the mutant to glucose addition during growth at $40 \mathrm{C}$ in succinate minimal medium. This behavior, coupled with the fact that glycerol must be phosphorylated by ATP to be metabolized (whereas succinate need not), suggested that the growth inhibition might be caused by a nonproductive phosphorylation of glucose that, in the absence of aldolase activity at $40 \mathrm{C}$, drained the cell of ATP. Some further suprort for this notion was gained by the finding that h8 cells growing on $\alpha$-glycerol phosphate at $40 \mathrm{C}$ were 
not inhibited at all by $10 \mu \mathrm{g} / \mathrm{ml}$ of glucose and only slightly by $100 \mu \mathrm{g} / \mathrm{ml}$. [That the cells actually take up $\alpha$-glycerol phosphate intact has been indicated by Lin et al. (18) and Hayashi et al. (12).]

Nevertheless, direct measurements of the ATP level in the soluble pool of the mutant under different conditions (Table 1) lead one to discount the "ATP-drain" hypothesis. The intracellular level of ATP dropped during inhibition by glucose or gluconate at $40 \mathrm{C}$, but the drop was neither large enough nor rapid enough to account for the growth inhibition. For example, the ATP level had dropped only $15 \%$ after growth had been completely inhibited for $5 \mathrm{~min}$.

On the other hand, the intracellular pool size of fructose-1,6-diphosphate rapidly increased 7to 20 -fold during growth inhibition (Table 1). This compound seemed to be the main sugar phosphate accumulated. No glucose-6-phosphate could be detected in cultures grown in glycerol or glucose minimal media at $30 \mathrm{C}$, although small amounts were found in cells inhibited at the high temperature. The strongest candidate for the role of intracellular inhibitor is therefore fructose1,6-diphosphate, the substrate of the damaged enzyme. One attempt was made to explore a possible site of inhibition by this compound. Since h8 cells grow on $\alpha$-glycerol phosphate but not on glycerol at $40 \mathrm{C}$ in the presence of glucose, the in vitro sensitivity of glycerol kinase from h8 cells to possible inhibitors like glucose, gluconate, glucose-6-phosphate, fructose-6-phosphate, and fructose-1,6-diphosphate was measured. Unfortunately, no appreciable sensitivity was found.

\section{Discussion}

The thermal inactivation of aldolase in mutant h8 at $40 \mathrm{C}$ not only prevents growth on glucose and related compounds, but also renders the cell hypersensitive to these substrates. The presence of glucose in the medium causes a complete cessation of all macromolecule synthesis (2). During this inhibition, glucose is metabolized in two stages. In the first stage, glucose disappears at 30 to $40 \%$ of the normal rate, but is converted only into other six-carbon compounds, such as gluconate, that are excreted into the medium. In the second stage, during which growth is still inhibited, the excreted metabolites are slowly taken up and completely oxidized, presumably via the hexose-monophosphate pathway. At the end of this stage, growth resumes on the original substrate. Throughout both of these stages of glucose metabolism at $40 \mathrm{C}$, the fructose-1,6diphosphate pool is maintained at a level more than 20-fold above normal. The intracellular ATP

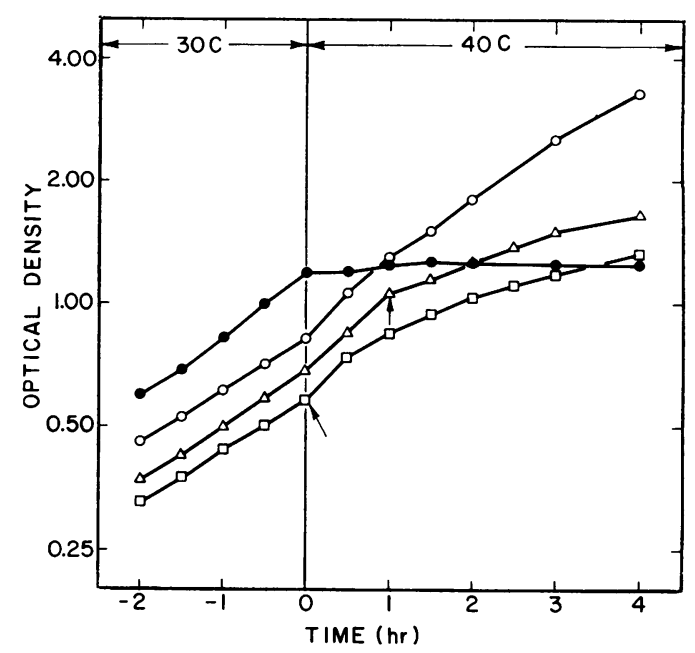

FIG. 7. Effect of glucose on the growth of h8 in succinate minimal medium after a shift of temperature from 30 to $40 \mathrm{C}$. Four cultures were shifted from 30 to $40 \mathrm{C}$ at zero-time; one received no glucose (O), one received glucose $1 \mathrm{hr}$ after the shift $(\triangle)$, one received glucose at zero-time ( $\square)$, and the fourth contained glucose from the beginning of the experiment (O).

TABLE 1. Effect of growth inhibition on the level of various phosphorylated metabolites in the soluble pool of mutant h8

\begin{tabular}{|c|c|c|c|c|}
\hline Medium & 密 & $\begin{array}{l}\text { "Appar- } \\
\text { ent" } \\
\text { ATP }\end{array}$ & $\begin{array}{l}\text { “True" } \\
\text { ATP } b\end{array}$ & $\begin{array}{l}\text { Fructose } \\
\text { diphos- } \\
\text { phate }\end{array}$ \\
\hline Glycerol $(0.4 \%)$. & $\begin{array}{c}C \\
40\end{array}$ & $3.1^{c}$ & 2.7 & 6.0 \\
\hline $\begin{array}{l}\text { Glycerol }(0.4 \%), 5 \\
\text { min of inhibition by } \\
\text { glucose }(0.2 \%) \ldots \ldots\end{array}$ & 40 & 2.7 & 2.3 & 42.0 \\
\hline $\begin{array}{l}\text { Glycerol }(0.4 \%), 30 \\
\quad \text { min of inhibition by } \\
\text { glucose }(0.2 \%) \ldots \ldots\end{array}$ & 40 & 2.2 & 2.0 & 44.0 \\
\hline $\begin{array}{l}\text { Glucose }(0.4 \%) \ldots \\
\text { Glucose }(0.4 \%), 60\end{array}$ & 30 & 3.6 & 1.6 & 8.0 \\
\hline $\min$ at $40 \mathrm{C}$ & 40 & 1.1 & 0.6 & 145.0 \\
\hline $\begin{array}{l}\text { Gluconate }(0.4 \%) \ldots \\
\text { Gluconate }(0.4 \%), 60\end{array}$ & 30 & 1.4 & 0.7 & 6.0 \\
\hline $\min$ at $40 \mathrm{C}$. & 40 & 1.0 & 0.5 & 140.0 \\
\hline
\end{tabular}

${ }^{a}$ Based on total light-producing capacity in the luciferase assay.

${ }^{b}$ Based on the light-producing capacity that was sensitive to glucose-hexokinase action.

c Results are expressed as millimicromoles per milligram of protein.

level drops during the growth inhibition, but the drop is neither rapid enough nor of sufficient magnitude to be a cause of the growth inhibition. It would appear, then, that the accumulation of 
fructose-1,6-diphosphate is somehow a cause of the sensitivity of these cells to glucose at $40 \mathrm{C}$.

It is not at all clear what sites are sensitive to the apparent poisoning by sugar phosphates. The metabolism of glycerol seems to be blocked at the very first step [glycerol phosphorylation, since entry of glycerol into the cells is by passive diffusion (13)], but no inhibition of glycerol kinase by fructose-1,6-diphosphate could be detected in cell free extracts. [N. Zwaig and E. C. C. Lin (Science, in press) have recently discovered that glycerol kinase in $E$. coli is sensitive to fructose-1,6-diphosphate, and that this sensitivity can be demonstrated in cell-free extracts at lower $p \mathrm{H}$ values than those employed here.] The total cessation of protein, ribonucleic acid (RNA), and deoxyribonucleic acid (DNA) synthesis in the presence of glucose at $40 \mathrm{C}$ occurs even in media supplemented with amino acids, nucleotides, and vitamins, indicating that one or more sensitive sites must exist in the polymerization reactions that use these monomers. Strain h8, however, like its parent, $\mathrm{K}-10$, has relaxed amino acid control over RNA synthesis. It would not be likely, therefore, for a primary lesion in protein (or DNA) synthesis to halt the synthesis of RNA. By this reasoning, one is led to the possibility that the intracellular pileup of sugar phosphates during aldolase insufficiency directly affects the synthesis of RNA. No supporting evidence can be given at this time.

Severe inhibition of growth by a substance whose catabolism is incomplete because of a mutationally or chemically blocked reaction has by now become a fairly common observation. Glucose toxicity similar to that reported here was observed recently in HeLa cells in which oxamate had blocked glycolysis (11). In this case, the toxicity was ascribed to a drop in the ATP level when glucose was added, but, as with our mutant, fructose-1,6-diphosphate was one of the compounds accumulated during the inhibition. Salmonella typhosa possesses rhamnose isomerase and rhamnulokinase but cannot grow on rhamnose. Addition of this sugar leads to rhamnulose - 1 - phosphate accumulation and growth inhibition $(1,9)$. Mutants of $E$. coli lacking the transferase, epimerase, or pyrophosphorylase but retaining the kinase of the galactose pathway are strongly inhibited by galactose, and galactose-1-phosphate accumulates $(17,23,24)$. Hereditary galactosemia in humans appears to have the same biochemical basis (21). Honeybees have an active hexokinase but no phosphomannose isomerase, and feeding mannose to them results in the accumulation of mannose-6phosphate and death (22). Feeding $L$-arabinose to $E$. coli mutants lacking L-ribulose-5-phosphate- 4-epimerase inhibits their growth, and ribulose5-phosphate accumulates (8). Similarly, glycerol is toxic to mutants of $E$. coli that lack $\alpha$-glycerophosphate dehydrogenase. These cells accumulate large quantities of $\alpha$-glycerophosphate during the inhibition $(5,13)$. In most of these cases, unlike our aldolase mutant, the addition of glucose tends to relieve the inhibition caused by the incompletely catabolized substrate.

It is interesting that mutant h8 can grow reasonably well on succinate or glycerol at $40 \mathrm{C}$. Biosynthesis of pentoses during growth on these compounds should require the action of aldolase. Two explanations may be suggested. First, there may be an as yet undiscovered alternate route to pentose from the three-carbon level, perhaps even a "biosynthetic" fructose-1,6-diphosphate aldolase that functions well in the direction of hexose (and pentose) synthesis. Second, it is possible that the aldolase of mutant h8 is damaged in such a way that, aside from being fully functional in situ at $30 \mathrm{C}$, it is perhaps $10 \%$ functional at $40 \mathrm{C}$, permitting some hexose and pentose synthesis from glycerol or succinate. In the presence of glucose, however, fructose-1,6diphosphate accumulation might then intensify the lesion by inactivating the residual aldolase activity.

One further point deserves comment. The inactivation of aldolase does not appear to stimulate h8 cells to expand any alternate routes of hexose catabolism. For example, if $E$. coli, like $S$. typhimurium, possesses an inducible Entner-Doudoroff pathway that would effectively bypass the aldolase step, one would expect this pathway to function in mutant h8, particularly during growth on gluconate (10). Nevertheless, mutant h8 cannot grow on gluconate at $40 \mathrm{C}$, and its growth on glycerol at $40 \mathrm{C}$ is totally inhibited by gluconate. At $40 \mathrm{C}$, fructose-1,6diphosphate accumulation is as great when gluconate is present as when glucose is. Either alternate routes cannot expand to meet the need, or, what seems more likely, an aldolase block always causes some diphosphate accumulation, and this compound inhibits alternate routes of carbohydrate metabolism.

\section{ACKNOWLEDGMENT}

This investigation was supported by Public Health Service research grant GM-08437 from the Division of General Medical Sciences.

\section{Literature Cited}

1. BARKULIS, I. L. 1949. Growth inhibition of Eberthella typhosa by certain carbohydrates and its release by mutation. J. Bacteriol. 58: 103-109. 
2. Böck, A., AND F. C. NeIDHARdT. 1966. Isolation of a mutant of Escherichia coli with a temperature-sensitive fructose-1,6-diphosphate aldolase. J. Bacteriol. 92:464-469.

3. Bublitz, C., AND E. P. Kennedy. 1954. Synthesis of phosphatides in isolated mitochondria. III. The enzymatic phosphorylation of glycerol. J. Biol. Chem. 211:951-961.

4. Chase, A. M. 1960. The measurement of luciferin and luciferase. Methods Biochem. Analy. 8: 61-117.

5. Cozzarelli, N. R., J. P. Кoch, S. Hayashi, AND E. C. C. LiN. 1965. Growth stasis by accumulated $\mathrm{L}$ - $\alpha$-glycerophosphate in Escherichia coli. J. Bacteriol. 90:1325-1329.

6. Dubois, M., K. A. Giles, J. K. Hamilton, P. A. Rebers, AND F. Smith. 1956. Colorimetric method for determination of sugars and related substances. Anal. Chem. 28:350-356.

7. Eidlic, L., AND F. C. Neidhardt. 1965. Protein and nucleic acid synthesis in two mutants of Escherichia coli with temperature-sensitive aminoacyl ribonucleic acid synthetases. J. Bacteriol. 89:706-711.

8. Englesberg, E., R. L. Anderson, R. Weinberg, N. Lee, P. Hoffee, G. Huttenhauer, AND H. BOYER. 1962. L-Arabinose-sensitive, L-ribulose 5-phosphate 4-epimerase-deficient mutants of Escherichia coli. J. Bacteriol. 84:137-146.

9. Englesberg, E., AND L. S. Baron. 1959. Mutation to L-rhamnose resistance and transduction to L-rhamnose utilization in Salmonella $t y$ phosa. J. Bacteriol. 78:675-686.

10. Fraenkel, D. G., AND B. L. Horecker. 1964. Pathways of D-glucose metabolism in Salmonella typhimurium. J. Biol. Chem. 239:27652771.

11. Goldberg, E. B., H. M. Nitowsky, AND S. P. Colowick. 1965. The role of glycolysis in the growth of tumor cells. IV. The basis of glucose toxicity in oxamate-treated cultured cells. J. Biol. Chem. 240:2791-2796.

12. Hayashi, S., J. P. Koch, and E. C. C. Lin. 1964. Active transport of $\mathrm{L}$ - $\alpha$-glycerophosphate in Escherichia coli. J. Biol. Chem. 239:3098-3105.

13. HAYASH, S., AND E. C. C. LiN. 1965. Capture of glycerol by cells of Escherichia coli. Biochim. Biophys. Acta 94:479-487.
14. Herzenberg, L. A. 1959. Studies on the induction of $\beta$-galactosidase in a cryptic strain of Escherichia coli. Biochim. Biophys. Acta 31: 525-538.

15. HoReCKer, B. L., AND W. A. WoOd. 1957. D-Glucose-6-phosphate, p. 152-154. In S. P. Colowick and N. O. Kaplan [ed.], Methods in enzymology, vol. 3. Academic Press, Inc., New York.

16. Imsande, J., And L. S. Prestidge. 1964. A crosslinked control system. II. Control of pyridine nucleotide formation in vivo. Biochim. Biophys. Acta 85:265-273.

17. KuRAhashi, K., AND A. J. Wahba. 1958. Interference with growth of certain Escherichia coli mutants by galactose. Biochim. Biophys. Acta 30:298-302.

18. LiN, E. C. C., J. P. Кoch, T. M. Chused, AND S. E. JORGENSEN. 1962. Utilization of $L-\alpha-$ glycerophosphate by Escherichia coli without hydrolysis. Proc. Natl. Acad. Sci. U.S. 48: 2145-2150.

19. Mandl, I., AND C. Neuberg. 1957. Ketohexose phosphates, p. 162-172. In S. P. Colowick and N. O. Kaplan [ed.], Methods in enzymology, vol. 3. Academic Press, Inc., New York.

20. MCFAyDEN, D. A. 1965. Estimation of formaldehyde in biological mixtures. J. Biol. Chem. 158:107-133.

21. Schwarz, V., L. Golberg, G. M. Komrower, AND A. Holzel. 1956. Some disturbances of erythrocyte metabolism in galactosaemia. Biochem. J. 62:34-40.

22. Sols, A., E. Cadenas, and F. Alvarado. 1960. Enzymatic basis of mannose toxicity in honey bees. Science 131:297-298.

23. Sundararajan, T. A., A. M. C. Rapin, and H. M. KALCKAR. 1962. Biochemical observations on $E$. coli mutants defective in uridine diphosphoglucose. Proc. Natl. Acad. Sci. U.S. 48:2187-2193.

24. Yarmolinsky, M. B., H. Wiesmeyer, H. M. KALCKAR, AND E. JORDAN. 1959. Hereditary defects in galactose metabolism in Escherichia coli mutants. II. Galactose-induced sensitivity. Proc. Natl. Acad. Sci. U.S. 45:1786-1791. 